\title{
The Impact of Planting Date on Management of the Rice Water Weevil in Louisiana Rice
}

\author{
M.J. Stout ${ }^{*}, 1$ N.A. Hummel ${ }^{1}$, M.J. Frey ${ }^{2}$ and W.C. Rice ${ }^{3}$ \\ ${ }^{I}$ Department of Entomology, Louisiana State University Agricultural Center, Baton Rouge, LA, 70803, USA \\ ${ }^{2}$ Rice Research Station, Louisiana State University Agricultural Center, Crowley, LA, USA \\ ${ }^{3}$ USDA, ARS, CPRL, Bushland, TX 79012, USA
}

\begin{abstract}
The rice water weevil, Lissorhoptrus oryzophilus, is the most destructive insect pest of rice in the United States. Early planting of rice to avoid damaging infestations of the rice water weevil has long been suggested as a management tactic. A five-year study was conducted to characterize the influence of rice planting date on rice water weevil management in light of recent trends toward earlier planting of rice in Louisiana. Experimental designs differed among years: experiments in 2001 and 2008 were split-plot studies, whereas in 2003, 2004, and 2007, separate randomized block experiments were conducted. Results from these experiments showed that early planting of rice facilitated rice water weevil management in three ways. Weevil infestations were lighter in rice planted in mid- to late March than in later-planted rice in three of five years of the study. In addition, yield losses attributable to weevil feeding were lower in early planted rice than in late planted rice in the two split-plot experiments. Finally, single applications of lambda-cyhalothrin (a pyrethroid applied to rice after flooding to kill weevil adults) were less effective in late planted rice than in early planted rice. This study demonstrates that early planting can serve as an important component of a management program for rice water weevils in Louisiana.
\end{abstract}

Keywords: Rice, Oryza sativa, rice water weevil, Lissorhoptrus oryzophilus, integrated pest management, planting date, early planting, insecticides.

\section{INTRODUCTION}

The rice water weevil (RWW), Lissorhoptrus oryzophilus Kuschel, is the most widely distributed and destructive earlyseason insect pest of rice, Oryza sativa L., in the United States [1]. It has recently invaded important rice-producing regions of Asia and Europe [2] and thus poses a global threat to rice production. The seasonal history of this insect begins in early spring, when adult RWWs emerge from overwintering sites, which include leaf litter, bunch grasses, and stubble in and around rice fields, and fly to rice fields [3]. Adult weevils feed on the leaves of rice, but this form of injury is not economically important except under unusually heavy infestations. Females oviposit primarily in leaf sheaths beneath the water surface [4]. Infestations of larvae thus commence when standing water is present in a rice field, a condition met after fields are flooded. Larvae may feed in or on leaves for a short period of time, but quickly move down to the roots, where they feed on or in the roots of rice. The insects pass through four instars and a pupal stage on roots in approximately 30 days [5]. Although populations of the weevil are multivoltine, only a single peak of larval abundance is usually observed in a rice field [3]. Feeding by larvae on the roots of rice plants results in reduced tillering and shoot growth in the vegetative phases of development, and reduced panicle densities and grain weights at harvest [6].

*Address correspondence to this author at the Department of Entomology, 404 Life Sciences Building, Louisiana State University, Baton Rouge, Louisiana, 70803, USA; Tel: (225) 578-1850; Fax: 578-1643;

E-mail: mstout @agctr.lsu.edu
Yield losses attributable to injury by this insect can exceed $20 \%$ [6].

The most commonly used tactic for managing L. oryzophilus is the application of insecticides. Prior to 1998, RWWs were managed with post-flood applications of carbofuran to eliminate larvae feeding on roots. Following the disallowance by the EPA of carbofuran in rice, several pyrethroids and a seed treatment of fipronil were registered for RWW control, targeting, respectively, the adult stage and larval stages of the insect [7]. The fipronil seed treatment was voluntarily removed from the market in 2004. Recently, newer seed treatments have been introduced for RWW control, including thiamethoxam and chlorantraniliprole seed treatments. All of the currently registered insecticides, especially the seed treatments, provide adequate protection against the RWW in most circumstances [7-9]. There may be, however, serious problems with the use of insecticides in rice, most notably negative effects on non-target invertebrates. Alternative tactics against the RWW are therefore needed.

Early planting has long been suggested as a management tactic against the RWW [10,11]. The basis for this suggestion is a potential asynchrony between rice planting, which begins in March in southwest Louisiana, and the emergence of weevils from overwintering sites. Emergence of adults from overwintering habitats in spring is influenced by temperature, beginning in late March to early April in southern rice-growing regions of the United States [5] and later in more northern rice-growing regions [12]. This emergence is 
a protracted process that may occur over the course of two or more months $[3,13]$. The nature and timing of RWW emergence suggests that early planting of rice may be a means of avoiding damaging weevil infestations. This cultural practice has been evaluated previously, with mixed results (e.g., $[14,15])$. However, in recent years, recommended planting dates have been moved forward in Louisiana and elsewhere [16], and there is need to re-evaluate this tactic in light of these revised recommendations. The series of experiments described here was conducted to evaluate the impact of planting date on RWW abundance, rice yields and yield losses, and insecticide efficacy in small rice plots.

\section{MATERIALS AND METHODS}

\section{General}

Experiments were conducted in 2001, 2003, 2004, 2007, and 2008 at the Louisiana State University Agricultural Center Rice Research Station located near Crowley, Acadia Parish, Louisiana. Experimental designs varied somewhat among years (Table 1); however, in all five years, grain yields and densities of RWW larvae and pupae were compared in insecticide-treated and untreated rice sown on two to four dates representing, at minimum, "early" and "mid" or "late" planting dates. "Early", "mid", and "late" planting dates were chosen with reference to the recommended range of optimum planting dates for southwest Louisiana, March 15 to April 20 [16], with early planting occurring in mid to late March, mid planting occurring in mid April, and late planting occurring in late April to early May. The effect of planting date on the severity of weevil infestations was evaluated by estimating densities of RWW larvae and pupae in rice planted on different dates. In addition, the inclusion of insecticide-treated plots in all experiments allowed yield losses to be compared among planting dates and also allowed investigation of the hypothesis that the efficacies of insecticide treatments varied with planting date.

Fields used in these experiments have been in rice-fallow rotation for over 20 years and the soil type in all fields was a
Crowley silt loam (fine smectitic, thermic, Typic Albaqualf). Agronomic practices used in all experiments were, unless otherwise noted, those recommended by the LSU AgCenter for southwest Louisiana [16]. Generally, fertilizer was applied at recommended rates as a pre-plant broadcast application of N-P-K fertilizer (7-21-21) and an additional broadcast application of $\mathrm{N}$ as urea $(46 \% \mathrm{~N})$ made just prior to flood establishment. Densities of L.oryzophilus larvae and pupae were estimated by removing two to four root/soil core samples from the interior of plots [5]. Core sampling was conducted once or twice for all experiments between three and five weeks after permanent flood. The core sampler was a metal cylinder with a diameter of $9.2 \mathrm{~cm}$ and a depth of 7.6 $\mathrm{cm}$ attached to a metal handle. Root/soil cores were placed into 40 mesh screen sieve buckets and soil and insects were washed from roots under pressure. Buckets were placed into basins with saturated salt water, and larvae and pupae were counted as they floated to the water surface. Rice was harvested using a small plot combine when rice grain reached a moisture content of 170 to $200 \mathrm{mg} \mathrm{g}^{-1}$. Rough rice grain yields were adjusted to a standard moisture content of 120 $\mathrm{mg} \mathrm{g}^{-1}$.

\section{Split-Plot Experiments: 2001 and 2008}

Experiments conducted in 2001 and 2008 were split-plot experiments, with planting date as the main-plot factor and insecticide treatment as the sub-plot factor. Replication of the planting date factor in main plots in this experimental design allowed the effects of planting date on densities of RWW larvae and pupae and on yields to be statistically analyzed.

2001 experiment: The main plot factor (planting date: early, mid, and late) was arranged as a randomized complete block with three replications. Main plots were separated by earthen levees and each main plot had separate access to a lateral for irrigation. The subplot factor was insecticide treatment (untreated or treated with the insecticidal seed treatment fipronil (Icon ${ }^{\circledR}$ 6.2 FS Bayer Crop Science]) and subplots were arranged randomly within main plots, with

Table 1. Experimental Designs and Dates of Planting, Flooding, and Insect Sampling for Planting Date Experiments Conducted from 2001 to 2008, LSU AgCenter Rice Research Station, Crowley, Louisiana

\begin{tabular}{|c|c|c|c|c|c|c|c|c|c|c|}
\hline \multirow[t]{2}{*}{ Year } & \multirow{2}{*}{$\begin{array}{c}\text { Experimen- } \\
\text { tal Design }\end{array}$} & \multicolumn{3}{|c|}{ Early Planting Date } & \multicolumn{3}{|c|}{ Mid Planting Date(s) } & \multicolumn{3}{|c|}{ Late Planting Date } \\
\hline & & Plant & Flood & $\begin{array}{c}\text { Core } \\
\text { samples }\end{array}$ & Plant & Flood & $\begin{array}{c}\text { Core } \\
\text { samples }\end{array}$ & Plant & Flood & $\begin{array}{c}\text { Core } \\
\text { samples }\end{array}$ \\
\hline 2001 & Split-plot & 27 March & 18 April & 9,21 May & 9 April & 30 April & $\begin{array}{l}21 \text { May, } 4 \\
\text { June }\end{array}$ & 30 April & 22 May & $\begin{array}{c}12,26 \\
\text { June }\end{array}$ \\
\hline $\begin{array}{c}2004 \\
\text { (water- } \\
\text { seeded) }\end{array}$ & $\begin{array}{l}\text { Separate RCB } \\
\text { experiments }\end{array}$ & 15 March & 14 April & 13 May & $\begin{array}{c}1 \text { April, } 14 \\
\text { April }\end{array}$ & $\begin{array}{l}30 \text { April, } \\
12 \text { May }\end{array}$ & $\begin{array}{l}26 \text { May, } 8 \\
\text { June }\end{array}$ & 30 April & 24 May & 22 June \\
\hline 2007 & $\begin{array}{c}\text { Separate RCB } \\
\text { experiments }\end{array}$ & 8 March & 11 April & 7, 17 May & 17 April & 10 May & 5, 14 June & - & - & - \\
\hline
\end{tabular}


three subplots of each treatment in each main plot. Thus, for each planting date, there were a total of 18 subplots, nine each of two insecticide treatments distributed over three main plots.

Early-, mid-, and late planted plots were sown on 27 Mar, 9 Apr, and 30 Apr, respectively. All subplots were drillseeded to a depth of $2 \mathrm{~cm}$ with the rice cultivar 'Cypress', a semi-dwarf long-grain, at a seeding rate of $101.25 \mathrm{~kg}$ of seed per hectare. Subplots measured $1.25 \mathrm{~m} \mathrm{(7} \mathrm{rows} \mathrm{at} 17.8 \mathrm{~cm}$ row spacing) by $7.6 \mathrm{~m}$. For seeds assigned to the insecticide treatment, Icon ${ }^{\circledR} 6.2 \mathrm{FS}$ was applied by hand shortly before sowing at a rate equivalent to $0.056 \mathrm{~kg}$ ai per hectare. Flood was established on $18 \mathrm{Apr}, 30 \mathrm{Apr}$, and 22 May for early-, mid-, and late planted plots, respectively. Plants possessed three to four fully-expanded leaves when flooded. Core samples were taken to estimate densities of weevils on two dates for each main plot. For early planted rice, core samples were taken on 9 May and 21 May (21 and 33 daf, respectively); for the mid-planting date, samples were taken on 21 May and 4 Jun (21 and 35 daf, respectively); for the late planting date, samples were taken on 12 and 26 Jun (21 and 35 daf, respectively. Early-, mid-, and late planted plots were harvested on $6 \mathrm{Aug}, 6 \mathrm{Aug}$, and 9 Sept, respectively).

2008 experiment: In this experiment, main plots (early vs. late planting dates) were arranged as a randomized complete block with three replications. The subplot factor was insecticide treatment (four treatments) with treatments arranged as a randomized complete block within main plots with two replications per main plot. Thus, for each planting date, there were a total of six subplots of each insecticide treatment. The four insecticide treatments included an untreated control, an insecticidal seed treatment of Dermacor $\mathrm{X}-100^{\circledR}$ (Rynaxypyr $^{\circledR}$ [chlorantraniliprole], DuPont Crop Protection), a single post-flood application of Karate $Z^{\circledR}$ (lamda-cyhalothrin, Syngenta Crop Protection), and two post-flood applications of Karate $Z^{\circledR}$.

Early-planted plots were drill-seeded with the variety 'Cocodrie' as described for the 2001 experiment on 24 Mar, while late planted plots were drill-seeded on 2 May. Subplot size in this experiment was $1.25 \mathrm{~m}$ (7 rows at $17.8 \mathrm{~cm}$ row spacing) by $5.5 \mathrm{~m}$, and subplots were surrounded by metal flashing to reduce movement of insecticides in water from subplot to subplot. Seeds assigned to the Dermacor treatment were treated by hand with Dermacor X-100 ${ }^{\circledR}$ at a rate of 0.03 $\mathrm{mg}$ ai per seed. Subplots assigned to both of the lambdacyhalothrin treatments were sprayed with lambdacyhalothrin with a backpack, $\mathrm{CO}_{2}$-powered sprayer at a rate of $0.034 \mathrm{~kg}$ ai per hectare a few hours after flooding, and the second application of lambda-cyhalothrin was made to appropriate subplots seven daf (late planted subplots) or eight daf (early planted subplots). Permanent flood was applied to early planted main plots on $24 \mathrm{Apr}$, and to late planted main plots on 28 May. Core samples were taken to estimate densities of weevils on two dates for each main plot. For early planted rice, core samples were taken on 20 and 29 May (26 and $35 \mathrm{daf}$ ); for the late planting date, samples were taken on 24 Jun and $1 \mathrm{Jul}$ (26 and 33 daf, respectively). Early and late planted plots were harvested on 7 and 19 Aug, respectively (yields were not taken from several plots due to poor stand establishment).

\section{Randomized Complete Block Experiments: 2003, 2004, and 2007 Studies}

In addition to the split-plot experiments described above, additional studies were conducted in 2003, 2004, and 2007. Studies in each of these years consisted of separate randomized block experiments planted on two or more dates. Each experiment was conducted in a separate leveed area with access to a lateral for irrigation. Within each experiment, plots treated or not treated with insecticides were arranged as randomized complete blocks with four to five replications. Densities of weevil larvae and pupae in plots were determined once or twice, between three and five weeks after flooding. Yields from plots were also determined at the end of the season. This design allowed the effects of insecticide treatment on weevil densities and yields to be analyzed statistically for each planting date separately, but did not allow statistical comparisons of weevil densities among planting dates. Nonetheless, a qualitative assessment of the effect of planting date on weevil densities was possible, because experimental designs, sampling procedures, and agronomic practices used for each experiment were similar.

2003 study: Separate experiments were drill-seeded (cv. 'Cocodrie') on 25 Mar, 16 Apr, and 8 May. Each of these experiments was a randomized complete block experiment with two treatments (insecticide-treated and control) and four replicates. Insecticide treatment consisted of a fipronil seed treatment at a rate of $0.0675 \mathrm{~kg}$ ai per hectare. The plot size in this experiment was $1.25 \mathrm{~m}$ by $5.8 \mathrm{~m}$ (7 rows at $17.8 \mathrm{~cm}$ drill spacing) and the seeding rate was $101 \mathrm{~kg} \mathrm{ha}^{-1}$. Permanent floods were applied on 1 May, 15 May, 5 Jun for the early, mid, and late planting dates, respectively. Three core samples were taken from plots to estimate densities of weevil larvae and pupae 27, 25, and 26 daf for the early, mid, and late planting dates, respectively. Entire plots were harvested on $28 \mathrm{Jul}, 14 \mathrm{Aug}$, and 8 Sept.

2004 study: In 2004, plots were water-seeded rather than drill-seeded as in other years. In other respects, however, this study was similar to the one conducted in 2003. The experimental design for experiments was a randomized block with two treatments (control and insecticide-treated) and five replications. Plots were seeded on 15 Mar, 1 Apr, 14 Apr, and 30 Apr. For water-seeding, pre-weighed aliquots of seeds (cultivar 'Cocodrie') were soaked in water for $24 \mathrm{hr}$ to induce germination. After removing seeds from soak water, seeds assigned to the insecticide treatment were treated with fipronil at a rate equivalent to $0.08 \mathrm{~kg}$ ai per hectare. Seeds were then cast into flooded, premeasured $1.2 \mathrm{~m} \times 6.1 \mathrm{~m}$ plots. Seeding rate was $157.5 \mathrm{~kg}$ seed per hectare. Plots were drained within $48 \mathrm{hr}$ of seeding to allow plants to establish. Permanent floods were established on 14 Apr, $30 \mathrm{Apr}, 12$ May, and 24 May. Plants possessed three to four fully expanded leaves at flooding. Because there were concerns about the efficacy of fipronil in a water-seeded cultural system, carbofuran granules (Furadan ${ }^{\circledR}$ 3G FMC Corporation) were applied to plots assigned to insecticide treatments 17 to 19 daf to further control weevils in these plots. Three core samples were taken from each plot for each planting date 27 to 29 daf to estimate densities of weevil larvae and pupae. Plots were harvested on $19 \mathrm{Jul}, 29 \mathrm{Jul}, 11 \mathrm{Aug}$, and 16 Aug.

2007 study: In 2007, separate experiments were drillseeded on 8 Mar (early planting) and 17 Apr (mid planting) 
using the variety 'Cocodrie' at $101.25 \mathrm{~kg}$ seed per hectare (wet weather conditions prevented a late planting in 2007, although a comparable experiment was water-seeded on 16 May). These drill-seeded experiments consisted of four treatments (untreated control and one, two, or four applications of lambda-cyhalothrin) arranged as a randomized complete block with four replications. Plot size in these two experiments was $1.25 \mathrm{~m}$ by $5.5 \mathrm{~m}$, and plots were surrounded by metal flashing to restrict movement of insecticides among plots. Permanent floods were applied on 11 Apr and 10 May for the two experiments. Rice plants possessed four true leaves at flooding in both experiments. Lambda-cyhalothrin applications were made by backpack sprayer to appropriate plots in both experiments one daf (single lambda-cyhalothrin treatment), one and seven daf (two lambda-cyhalothrin applications), and one daf and every four to five days thereafter (four lambda-cyhalothrin applications). Core sampling dates for each experiment were as follows (four or five core samples from each plot on each date): early planting, 7 May (26 daf) and 17 May (36 daf); mid planting, 5 Jun (26 daf) and 14 Jun (35 daf).

\section{Statistical Analyses}

Rice water weevil counts from two to five core samples per plot per sampling date were averaged to obtain a mean density (larvae and pupae per core sample). Mean larval/pupal densities were analyzed by mixed-effects linear model ANOVA using PROC MIXED in SAS [20] as appropriate for a split-plot experimental design (planting date and insecticide treatment as fixed effects, block as a random effect) or randomized block design (insecticide treatment as a fixed effect, block as a random effect, with data from each planting date analyzed separately). When core samples were taken on more than one occasion in an experiment, the data from each core sampling were analyzed separately. Yield data were analyzed similarly using PROC MIXED in SAS. Means were separated using Tukey-Kramer mean comparisons.

\section{RESULTS}

\section{Split-Plot Studies: 2001 and 2008}

2001 experiment: There was a significant trend toward higher densities of RWW larvae and pupae at later planting dates in 2001 (Table 2, Fig. 1). This trend was evident in core samples taken three and five weeks after flooding (first and second core samplings), although the main effect of planting date was significant only for core samples taken five weeks after flooding (Table 2). Treatment of seeds with the insecticide fipronil resulted in a significant reduction in weevil densities in core samples taken at both three and five weeks after flooding (Table 2). However, a significant insecticide by planting date interaction for both the three- and five-week core samplings indicates that the effect of insecticide varied with planting date. For the three-week core sampling, differences in weevil densities between treated and untreated subplots were significant only for the late planting date, but for core samples taken five weeks after flooding, differences in weevil densities between insecticide-treated and untreated subplots were significant for all three planting dates (Fig. 1). For the five-week core samplings, the absolute differences in larval densities between treated and untreated plots were greatest in late planted plots. When the efficacy of insecticidal seed treatments is expressed as a percent reduction in insect densities, insecticide effectiveness was greater at the early planting date: reduction in insect densities exceeded $86 \%$ at the early planting date, and averaged about $80 \%$ at the mid- and late planting dates.

Yields in 2001 were significantly higher from plots planted at the early planting date than from plots planted at either the mid- or late planting date (Fig. 1c, Table 2). Yields from insecticide-treated plots were higher than yields from untreated plots at the early and late planting dates but not at the mid planting date. Percent differences in yields between insecticide-treated and untreated plots were higher at the late planting date $(27.6 \%)$ than at the early planting date $(12.7 \%)$.

2008 experiment: The main plot effect of planting date was significant for core samples taken 26 daf and marginally significant for core samples taken 33-35 daf, indicating that overall densities of RWW larvae and pupae were higher in late planted subplots than in early planted subplots (Table $\mathbf{2}$, Fig. 2). However, differences in weevil densities in untreated plots were small; it was in the insecticide-treated subplots that the planting date effect was most evident. Treatment of plots with insecticides significantly reduced overall weevil densities at both 26 daf and 33-35 daf. Moreover, the effect of insecticide treatment differed with planting date in both

Table 2. Analysis of Variance of Larval Densities (Larvae and Pupae Per Core Sample) and of Yields from Split-Plot Experiments Designed to Investigate the Effects of Planting Date in 2001 and 2008, LSU AgCenter Rice Research Station, Crowley, Louisiana

\begin{tabular}{|c|c|c|c|c|c|c|c|c|c|}
\hline Source of Variation & \multicolumn{3}{|c|}{ Core Sampling 1} & \multicolumn{3}{|c|}{ Core Sampling 2} & \multicolumn{3}{|c|}{ Yields } \\
\hline \multicolumn{10}{|c|}{2001 experiment } \\
\hline planting date (pd) & 2,4 & 4.9 & 0.08 & 2,4 & 25.2 & 0.005 & 2,4 & 335.9 & $<0.0001$ \\
\hline Insecticide treatment $(\mathrm{t})$ & 1,42 & 25.5 & $<0.0001$ & 1,42 & 186.3 & $<0.0001$ & 1,42 & 53.3 & $<0.0001$ \\
\hline planting date (pd) & 1,10 & 12.8 & 0.005 & $1,8.01$ & 3.9 & 0.08 & 1,4 & 11.8 & 0.03 \\
\hline Insecticide treatment $(t)$ & 3,30 & 33.5 & $<0.0001$ & 3,30 & 51.1 & $<0.0001$ & 3,12 & 11.4 & 0.001 \\
\hline $\mathrm{pd} \times \mathrm{t}$ & 3,30 & 3.1 & 0.04 & 3,30 & 4.0 & 0.02 & 3,12 & 4.0 & 0.03 \\
\hline
\end{tabular}


$1 \mathbf{a}$

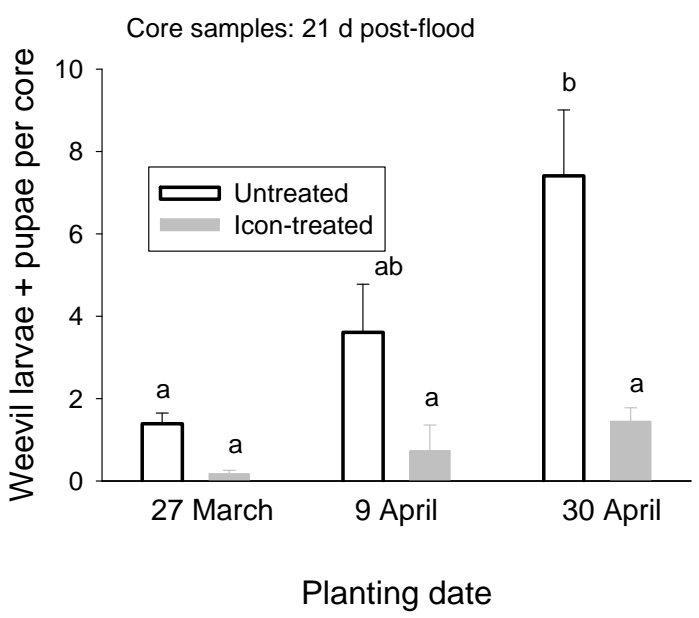

$1 \mathbf{b}$

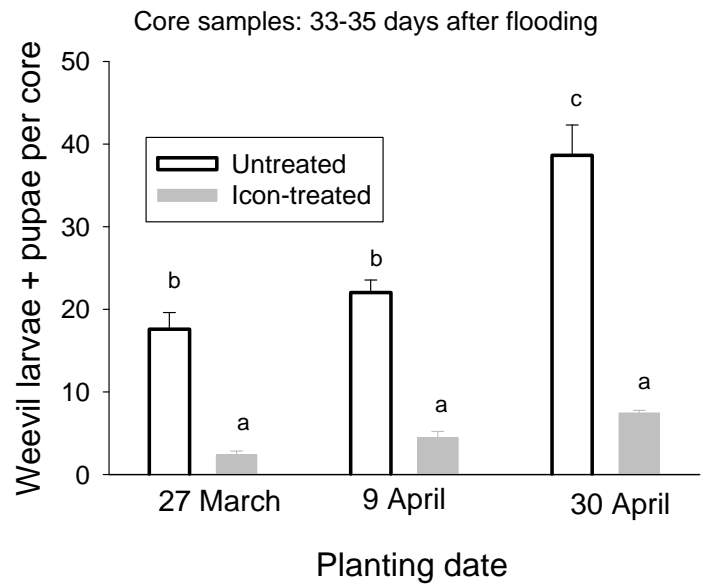

1c

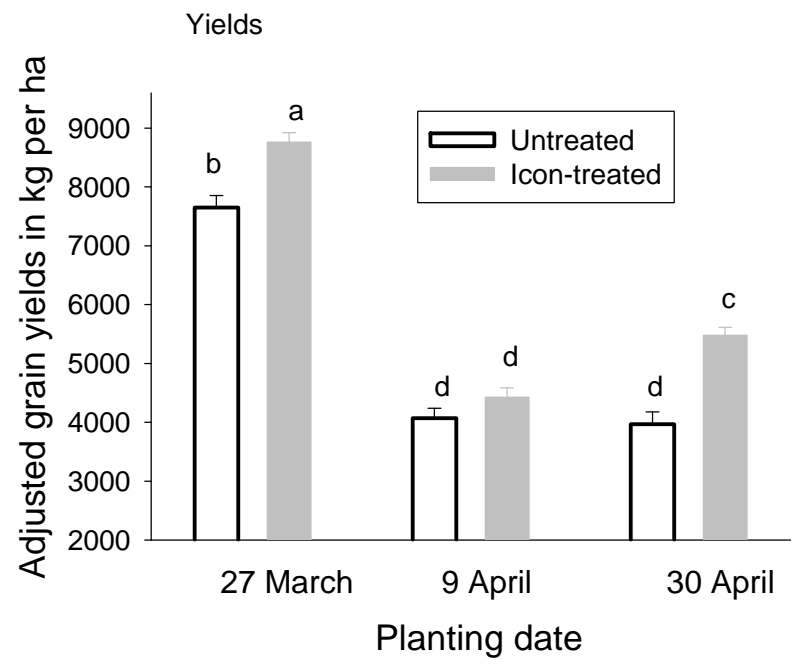

Fig. (1). Influence of planting date and insecticide treatment on densities of rice water weevil larvae and pupae (1a, 1b) and on grain yields (1c) in a planting date experiment conducted in 2001 at the LSU AgCenter Rice Research Station, Crowley, Louisiana. Densities of rice water weevil larvae and pupae (larvae and pupae per core sample + s.e.) were determined 21 (1a) and 33-35 days after flooding (1b) for each planting date. Bars accompanied by different letters designate means that differed significantly (Tukey's mean separation).

the $26 \mathrm{~d}$ and 33-35 daf core samples. For core samples taken 26 daf, insecticide treatments (especially lambda-cyhalothrin applications) were more effective at reducing weevil densities in early planted subplots than in late planted subplots (Fig. 2a). Similarly, for core samples taken 33-35 daf, single applications of lambda-cyhalothrin were more effective in early planted subplots than in late planted subplots (Fig. 2b).

The analysis of the 2008 yield data showed that subplot yields were significantly affected by planting date (Table 2 ). Overall, yields were higher from early planted subplots than from late planted subplots. At the early planting date, there were no significant differences (as indicated by TukeyKramer comparisons) in yields among untreated and insecticide-treated plots. At the late planting date, however, yields were highest from Dermacor ${ }^{\circledR} \mathrm{X}$-100-treated plots, intermediate from plots treated twice with lambda-cyhalothrin, and lowest in untreated plots and plots treated once with lambdacyhalothrin.
Separate Randomized Complete Block Studies: 2003, 2004, and 2007

Studies in 2003, 2004 and 2007 consisted of separate randomized block experiments planted at two, three or four dates. Replication of insecticide treatments within each planting date experiment allowed statistical analyses of the effect of insecticide treatment for each experiment, but lack of replication of planting date in these experiments precluded anything more than a qualitative analysis of the effect of planting date.

2003 experiments: Weevil densities in untreated plots were similar among planting dates in 2003 (Table 3). Treatment of seeds with fipronil reduced densities of weevil larvae and pupae 25 to 27 daf at the early and mid planting dates but not at the late planting date-i.e., the fipronil treatment was effective at the first two planting dates but not the late planting date. Yields were significantly higher from 
$2 \mathbf{a}$

Core samples: 26 days after flooding

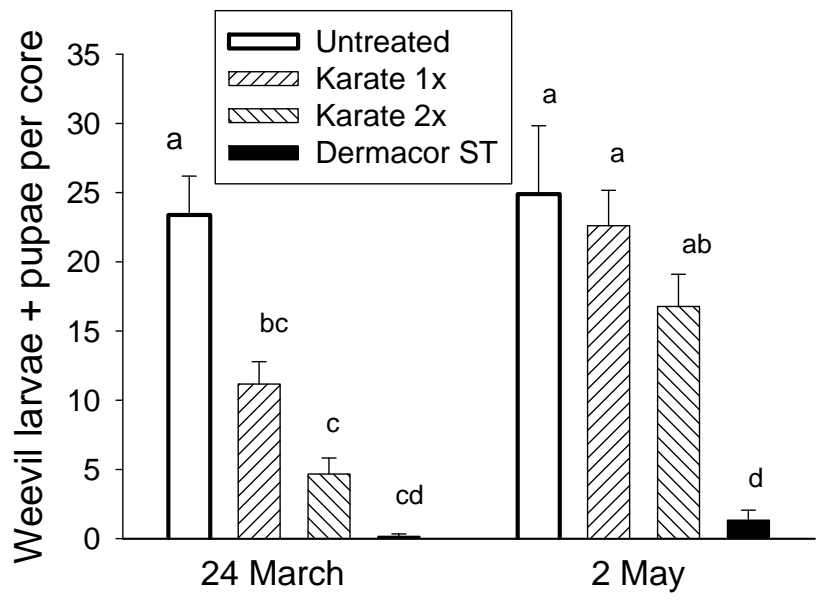

Planting date
$2 \mathbf{b}$

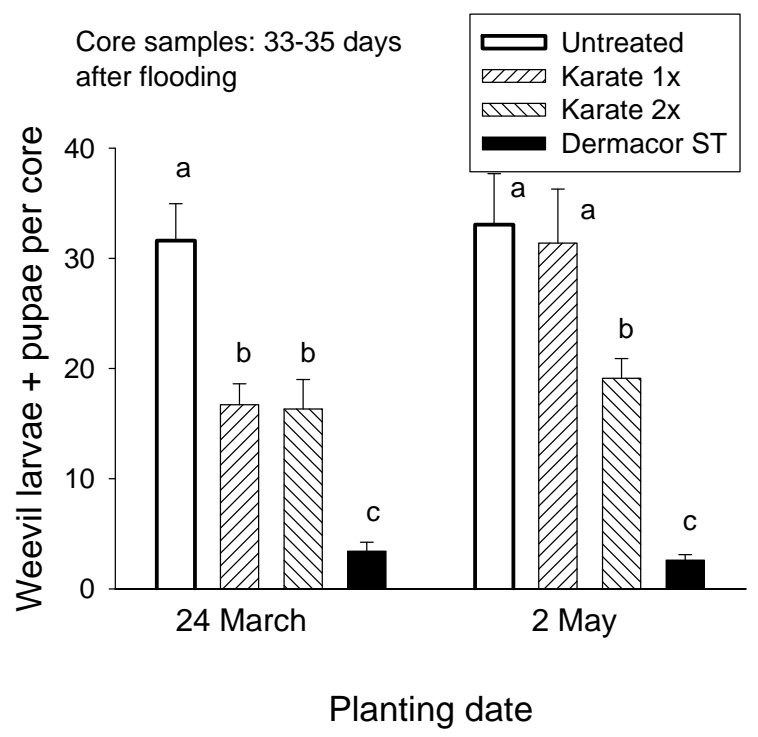

2c

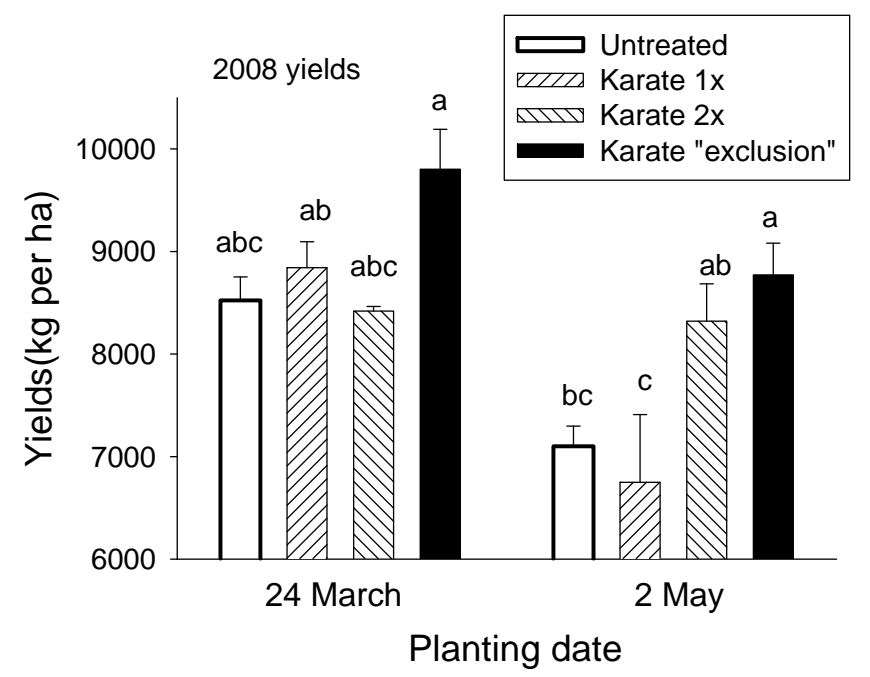

Fig. (2). Influence of planting date and insecticide treatment on densities of rice water weevil larvae and pupae (2a, 2b) and on grain yields (2c) in a planting date experiment conducted in 2008 at the LSU AgCenter Rice Research Station, Crowley, Louisiana. Densities of rice water weevil larvae and pupae (larvae and pupae per core sample + s.e.) were determined 26 days after flooding (2a) and 33-35 days after flooding (2b) for each planting date. Bars accompanied by different letters designate means that differed significantly (Tukey's mean separation).

Icon-treated than from untreated plots at the mid and late planting dates but not the early planting date. When expressed on a percent basis, differences in yields between treated and untreated plots increased with planting date, with a $14.7 \%$ reduction in the early planting date, a $22.1 \%$ reduction at the mid planting date, and a $32.9 \%$ reduction at the late planting date.

2004 experiments (water-seeded): Densities of RWW larvae and pupae in untreated plots 27 to 29 days after flooding were very low in plots planted on the earliest planting date, highest in plots planted two weeks later, and intermediate in plots from the last two planting dates (Table 3 ). Treatment of seeds with insecticides significantly reduced weevil densities in plots in all four experiments $(\mathrm{P}<0.01)$. Yields were higher from insecticide-treated plots at all four planting dates (Table 3), but only for the second date was the difference in yields significant.
2007 experiments: Densities of weevil larvae and pupae in untreated plots were higher in the experiment planted on 17 Apr than in the experiment planted on 8 Mar, especially for the core samples taken 26 daf (Fig. 3). (Densities were higher yet in a comparable water-seeded experiment planted on 16 May; data not shown). Insecticide treatment significantly reduced weevil densities in both the early and midplanted experiments $(\mathrm{P}<0.01$ for both experiments for both core samplings), but the patterns differed between the two experiments. For the experiment planted on $8 \mathrm{Mar}$, one, two, and four applications of lambda-cyhalothrin significantly reduced densities of larvae below densities observed in untreated plots on the 26 daf core sampling; however, for the 17 Apr planting, single applications of lambda-cyhalothrin failed to significantly reduce weevil densities below those found in untreated plots on the 26 daf core sampling. For the core samplings taken 35-36 daf, the efficacy of four applica- 
Table 3. Larval densities (larvae and pupae per core sample \pm s.e.), yields (kg per ha \pm s.e.), and \% yield losses from separate randomized block experiments with different planting dates, 2003 and 2004, LSU AgCenter Rice Research Station, Crowley, Louisiana. Means from insecticide-treated plots accompanied by an asterisk are significantly different than corresponding means from untreated plots

\begin{tabular}{|c|c|c|c|c|c|c|}
\hline \multirow[b]{2}{*}{ Experiment } & \multirow[t]{2}{*}{ Date of Planting } & \multicolumn{2}{|c|}{$\begin{array}{l}\text { Larval Densities, 25-29 Days After } \\
\text { Flood: }\end{array}$} & \multicolumn{2}{|c|}{ Yields in kg ha-1 } & \multirow{2}{*}{$\begin{array}{c}\text { \% Yield } \\
\text { Difference } \\
{[(\mathbf{I}-\mathbf{U}) / \mathbf{I}] \mathbf{x 1 0 0}}\end{array}$} \\
\hline & & Untreated & Insecticide-treated & Untreated (U) & Insecticide-treated (I) & \\
\hline \multirow[t]{2}{*}{2003 (drill-seeded) } & 25 March & $21.2 \pm 1.5$ & $2.9 \pm 0.6^{*}$ & $8050.2 \pm 641.5$ & $9432.6 \pm 117.0$ & $14.7 \%$ \\
\hline & 16 April & $19.9 \pm 2.6$ & $1.0 \pm 0.3^{*}$ & $5126.5 \pm 284.5$ & $6581.7 \pm 360.1^{*}$ & $22.1 \%$ \\
\hline \multirow{3}{*}{$\begin{array}{c}2004 \\
\text { (water-seeded) }\end{array}$} & 15 March & $2.0 \pm 0.3$ & $0.13 \pm 0.1 *$ & $4546.8 \pm 868.3$ & $4852.4 \pm 488.2$ & $6.3 \%$ \\
\hline & 1 April & $16.2 \pm 2.6$ & $2.2 \pm 1.0 *$ & $4670.7 \pm 405.7$ & $6600.4 \pm 484.8^{*}$ & $29.2 \%$ \\
\hline & 14 April & $12.9 \pm 2.8$ & $2.1 \pm 0.4^{*}$ & $7604.9 \pm 315.9$ & $8070.5 \pm 53.7$ & $5.8 \%$ \\
\hline
\end{tabular}

tions of Karate $\mathrm{Z}$ was reduced in the experiment planted on 17 Apr (69\% reduction relative to control) compared to the experiment planted on 8 Mar (82\% reduction relative to control). Yields did not differ with treatment in either the early or mid-planted experiment (data not shown).

\section{DISCUSSION}

Early planting facilitated weevil management in all five years of the study. In three of five years (2001, 2004, and 2007), densities of RWW larvae and pupae in plots not treated with insecticide increased as a function of planting date. In fact, in all three of these years, at the early planting dates, densities of weevil larvae and pupae in intital core samples (generally taken three to four weeks after flooding) were at or below levels considered to be economically damaging (three to five larvae and pupae per core sample), showing that early planting is sometimes a means of avoiding damaging infestations of weevil larvae, or at least delaying such infestations until rice is older. Furthermore, patterns of yields and yield losses generally support the idea that the yield impact of weevil infestations was lower in early planted rice. In both 2001 and 2008 (the two split-plot experiments from which the strongest inferences can be made), yields were higher from early planted plots than from late planted plots, and yield reductions attributable to weevil infestations were also lower from early planted plots (ca. 13\%) than from late planted plots (19-28\%). This pattern was also observed in the separate randomized block experiments conducted in 2003 (Table 3). Finally, experiments conducted in 2007 and 2008 provided evidence that single applications of lambda-cyhalothrin were more effective in reducing densities of weevil larvae and pupae in early planted experiments than in late planted experiments. This is the first report of an effect of planting date on insecticide efficacy in rice.

The patterns of RWW abundance observed in these experiments are explicable by reference to published descriptions of RWW behavior and biology. Emergence from overwintering by RWWs is, like other processes in insects, dependent on temperature $[5,12]$. In prior studies, emergence of weevils from overwintering was found to begin in late March in southwest Louisiana [5] and mid-April in Arkansas $[12,13]$. However, weevil emergence from overwintering is a protracted process that is not complete until two or more months after it begins $[3,12]$. Thus, fields planted and flooded sufficiently early in the season, when weevil populations have not completely emerged from overwintering sites, are subject to infestation by smaller populations than are fields planted and flooded later, when all or nearly all overwintering weevils have emerged from overwintering sites. This is likely the primary explanation for smaller weevil populations in early planted plots than late planted plots in three of five years in this study. In addition, early planting of rice may allow rice to develop past the mid-tillering stage of growth, the stage most preferred for weevil oviposition [17], before a large weevil population begins infesting rice fields.

Published information about RWW biology also explains why applications of lambda-cyhalothrin had reduced efficacy in late planted fields [7]. Once they have emerged from overwintering sites, RWWs may live for several months or more, and may move from field to field to feed and reproduce $[3,18]$. Furthermore, weevils may complete their immature stages within 30 days [5]. Late-planted rice is thus potentially subject to infestation by weevils from three sources (overwintering-generation weevils arriving from other rice fields, first generation weevils arriving from other rice fields, and, perhaps, late-emerging, overwintering-generation weevils arriving directly from overwintering sites), whereas early planted fields are generally invaded only by weevils arriving directly from overwintering sites. As a result, immigration of RWWs to late planted fields tends to occur sooner after flooding and over a more extended period of time than does immigration to early planted rice [3]. Applications of pyrethroids like Karate Z, which have limited residual activity, may therefore eliminate a lower proportion of adult weevils in late planted fields than in early planted fields.

Early planting has been suggested as a management tactic for the RWW by numerous authors over the past 80 years $[3,10,11,14,15]$. Initially, this tactic was viewed only as a 
3a

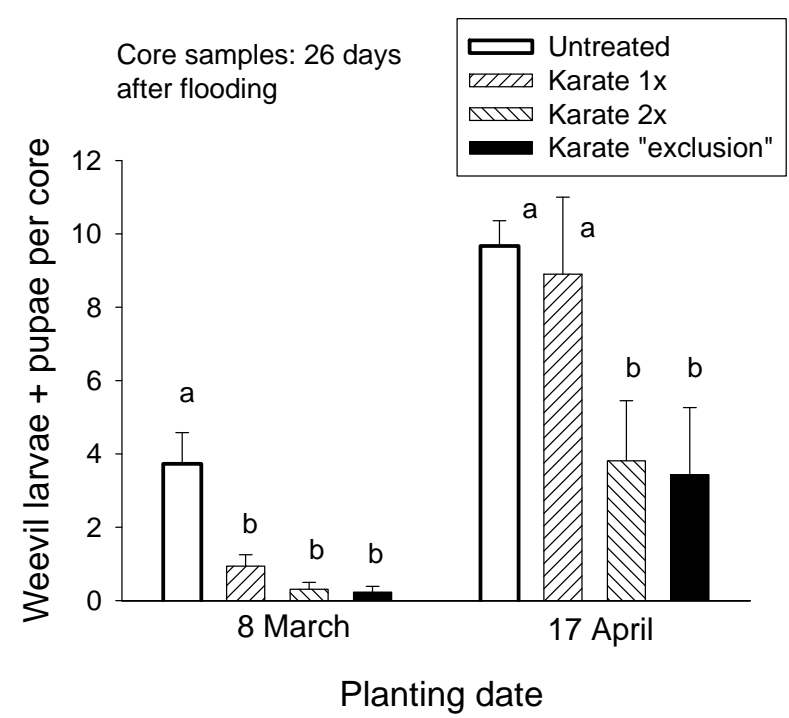

$3 \mathbf{b}$

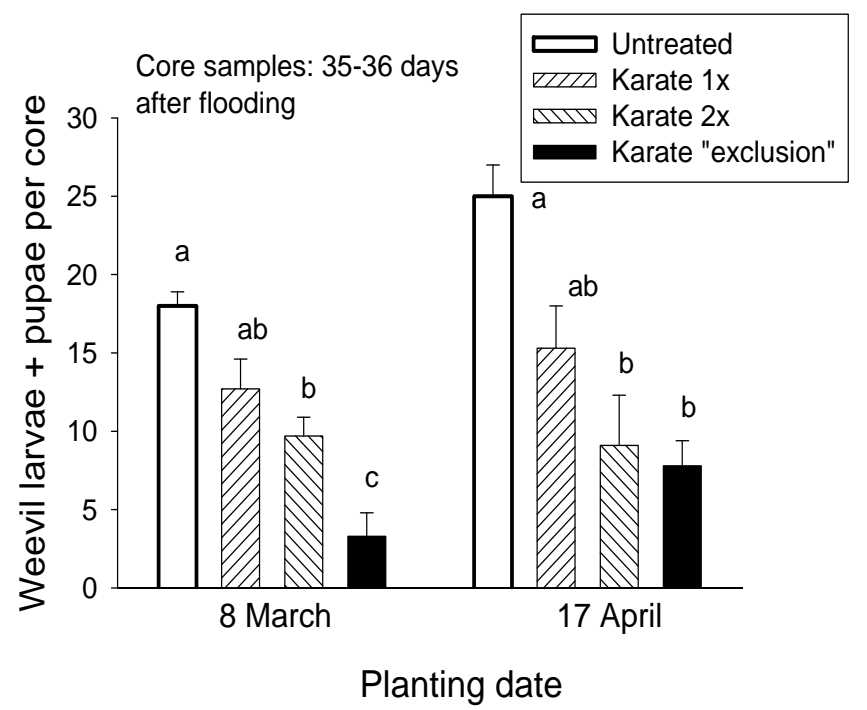

Fig. (3). Influence of insecticide treatment on densities of rice water weevil larvae and pupae (2a, 2b) in separate randomized block experiments sown on two dates in 2007 at the LSU AgCenter Rice Research Station, Crowley, Louisiana. Densities of rice water weevil larvae and pupae (larvae and pupae per core sample + s.e.) were determined 26 days after flooding (3a) and 35-36 days after flooding (3b) for each experiment. For each planting date, bars accompanied by different letters designate means that differed significantly (Tukey's mean separation).

means of reducing weevil populations in rice fields. In this study as well as prior studies, the hypothesis that early planting is associated with lower populations of weevil larvae in untreated rice has received mixed support $[10,14,15]$; that is, the pattern is observed in some years (e.g., 2001) but not others (e.g., 2003). However, in some studies that did not find lower weevil densities in "early" planted plots (e.g. [14]), rice was probably not planted early enough to result in asynchrony between rice development and weevil emergence.

Thompson et al. [14] introduced the notion that early planted rice could better tolerate injury by weevil larvae by showing that yield reductions were lower in early planted rice than in late planted rice in a two-year study. Recently, Espino et al. [15] analyzed data from experiments conducted over a six-year period in Texas and found that the relationship between density of RWW larvae and pupae and yield loss did not vary with planting date, a result seemingly at odds with that of Thompson et al. [14]. Our observation of reduced yield losses (on a percent basis) in early planted rice in 2001 and 2008 is consistent with the hypothesis that early planted rice is more tolerant of weevil injury than late planted rice, although in 2001 reduced yield losses could be also attributed to lower larval populations in early planted rice. Rice appears to be more tolerant of RWW larval feeding at later stages of plant development than at earlier stages of development [19], perhaps explaining why early planted rice, in which infestation by weevil larvae is sometimes delayed until rice plants are older, in some cases appears to be more tolerant of weevil injury. However, it is difficult to disentangle the overall positive effects of early planting on rice yield [15] from a putative increase in tolerance to RWW injury in early planted rice, and more research will be re- quired to clarify the impact of early planting on rice tolerance to weevil injury.

The finding that a single application of the pyrethroid lambda-cyhalothrin was not always effective at reducing weevil populations below threshold levels when weevil populations were high (for instance, in late planted rice in 2007 and in both early and late planted rice in 2008) has important implications for RWW management programs. First, this result provides additional justification for planting rice early (within the range of recommended planting dates): because weevil populations are more likely to be low in early planted rice, early planting potentially allows farmers a wider choice of effective insecticides. Furthermore, this result demonstrates that, when planting rice late, rice farmers should use seed treatments rather than foliar applications of pyrethroids for weevil management, because weevil populations are often high in late planted rice and applications of pyrethroids have reduced efficacy under such conditions. Recently, two seed treatments (Dermacor X-100 ${ }^{\circledR}$ and Cruis$\operatorname{erMaxx}^{\circledR}$ ) have been registered for use in rice and have proven effective in small-plot and commercial-scale trials (Stout and Hummel, unpublished data).

\section{CONCLUSIONS}

The results of this study provide evidence that planting rice earlier within the recommended range of planting dates contributes to weevil management in three ways. First, early planted rice is often subject to lower levels of infestation. Second, early planted fields sometimes suffer lower yield losses from weevils, perhaps because planting rice early in the recommended planting window allows rice to grow past the most susceptible growth stages before migration of weevils from overwintering sites. Third, early planting allows greater flexibility in use of insecticides. Early-planted fields 
can be effectively treated with foliar insecticides, which are a much more affordable treatment option than seed treatment alternatives.

\section{ACKNOWLEDGMENTS}

The authors thank Dr. D. Blouin for advice on statistics, Mr. Ryan Pousson for assistance with experiments, and five anonymous reviewers for comments on a previous draft of the manuscript. This research was supported by grants to MJS from the Louisiana Rice Research Board and the USDA Biologically Based Pest Management and Pest Management Alternative Programs.

\section{ABBREVIATION}

daf $=$ days after flooding

\section{REFERENCES}

[1] Way MO. Insect pest management in rice in the United States, In: Grayson BT, Green MB, Copping LG, Eds. Pest management in Rice. Barking, UK: Elsevier Applied Science Publishers 1990; pp. 181-189.

[2] Saito T, Hirai K, Way MO. The rice water weevil, Lissorhoptrus oryzophilus Kuschel (Coleoptera: Curculionidae). Appl Entomol Zool 2005; 40: 31-39.

[3] Shang H, Stout MJ, Zhang Z, Cheng J. Rice water weevil (Coleoptera:Curculionidae) population dynamics in Louisiana. J Entomol Sci 2004; 39: 623-42.

[4] Stout MJ, Riggio MR, Zou L, Roberts R. Flooding influences ovipositional and feeding behavior of the rice water weevil (Coleoptera:Curculionidae). J. Econ Entomol 2002; 95: 715-21.

[5] Zou L, Stout MJ, Ring DR. Degree-day models for emergence and development of the rice water weevil (Coleoptera: Curculionidae) in southwestern Louisiana. Environ Entomol 2004; 33: 1541-8.

[6] Zou L, Stout MJ, Dunand RT. The effects of feeding by the rice water weevil, Lissorhoptrus oryzophilus Kuschel, on the growth and yield components of rice, Oryza sativa. Agric For Entomol 2004; 6: 47-53.

[7] Stout MJ, Rice WC, Riggio RM, Ring DR . The effects of four insecticides on the population dynamics of the rice water weevil, Lissorhoptrus oryzophilus Kuschel. J Entomol Sci 2000; 35: 48-61.
[8] Hummel N, Stout MJ. Rice water weevil control with Dermacor X100 seed treatment, 2008. Arthropod Management Tests 2008 [serial on the internet]. Available from: http://www.entsoc.org/Protected/AMT/AMT34/

[9] Stout MJ, Frey MJ. Evaluation of thiamethoxam as a seed treatment against the rice water weevil. Ann Res Rpt Rice Res Stn LSU Agric Ctr 2007; 99: 299-300.

[10] Isley D. Schwardt HH. The rice water weevil. Arkansas Agricultural Experiment Station Bulletin 1934; 299: 1-44.

[11] Bowling CC. Insect pests of rice in the United States, In: The major insect pests of the rice plant. Proceedings, Symposium International Rice Research Institute, Los Bantos, Philipines, September 1964. Johns Hopkins Press, Baltimore, MD, 1967; 551-70.

[12] Morgan DR, Slaymaker PH, Robinson JF, Tugwell NP. Rice water weevil (Coleopteran: Curculionidae) indirect flight muscle development and spring emergence in response to temperature. Environ Entomol 1984; 13: 26-8

[13] Muda ARB, Tugwell NP, Haizlip MB. Seasonal history and indirect flight muscle degeneration in the rice water weevil. Environ Entomol 1981; 10: 685-690.

[14] Thompson RA, Quisenberry SS, N'guessan FK, Heagler AM, Giesler G. Planting date as a potential cultural method for managing the rice water weevil (Coleoptera: Curculionidae) in waterseeded rice in southwest Louisiana. J Econ Entomol 1994; 87: 1318-24.

[15] Espino L, Way MO, Pearson R, Nunez M. Effect of planting date on Lissorhoptrus oryzophilus (Coleoptera Curculionidae) density yield relationship on rice in southeastern Texas. J Econ Entomol 2009; 102: 1536-45.

[16] Blanche B, Harrell D, Saichuk J. General agronomic guidelines. In: Louisiana rice production handbook, Saichuk J Ed. LSU Agric Ctr Publ 2321, LSU AgCenter, Baton Rouge, LA, 2009; 3-15.

[17] Bang YH, Tugwell NP. Adult rice water weevil feeding preferences for rice plants and leaves of different ages. Arkansas Agricultural Experiment Station. Rep Ser 231, 1976; 1-12.

[18] Nilakhe SS. Reproductive status of overwintering rice water weevils. Ann Entomol Soc Am 1977; 70: 599-601.

[19] Stout MJ, Rice WC, Ring DR. The influence of plant age on the tolerance of rice to injury by the rice water weevil. Bull Entomol Res 2002; 92: 177-84.

[20] SAS Institute. SAS/STAT User's guide, release 9.1. SAS Institute, Cary, North Carolina 2004.

(C) Stout et al.; Licensee Bentham Open.

This is an open access article licensed under the terms of the Creative Commons Attribution Non-Commercial License (http://creativecommons.org/licenses/by-nc/3.0/) which permits unrestricted, non-commercial use, distribution and reproduction in any medium, provided the work is properly cited. 